\title{
Sensory Evaluation and Production Cost of Almond Milk Shake
}

\author{
D.D. Kuchekar, S.G. Narwade and S.V. Gaikwad* \\ Department of Animal Husbandry \& Dairy Science, Vasantrao Naik Marathwada Krishi \\ Vidyapeeth, Parbhani, 431402 (M.S.), India \\ *Corresponding author
}

\begin{tabular}{|l|}
\hline K e y w o r d s \\
Almond, Buffalo \\
milk, Sugar, \\
Chemical \\
composition, Cost \\
of product
\end{tabular}

Milk shake is a frozen dairy product, prepared from milk and ice cream mixing into mixer to make it pourable and generate foam in it. It can be made more nutritious and health protector with addition of almond (Prunus dulcis) due to its rich mineral contents, zero cholesterol level, and health invigorating antioxidant, anti-cancerous and antibacterial properties against harmful pathogens. There has been no scientific study on milk shake blended with almond (Prunus dulcis) particularly from buffalo milk, which is more nutritious, and rank higher with respect to sensory appeal over cow milk. Milk shake was prepared from different proportions of milk shake from buffalo milk blended with crushed almond viz. $5 \%, 10 \%$ and $15 \%$. Comparison between the treatment samples revealed that milk shake with $5 \%$ almond had significantly $(\mathrm{P}<0.05)$ higher in Colour and appearance $(8.33 \%)$, Flavour $(8.52 \%)$ and Body and Texture $(8.49 \%)$ than the other two levels $(5 \%$ and $10 \%$ almond). The overall acceptability score (8.44) was the highest in the sample with 5\% almond. The production cost of milk shake with 5\% almond (Rs.99.5) was lower than the other two samples. The study tends to conclude that milk shake prepared from buffalo milk with a blend of 5\% almond was more consumer-friendly than buffalo milk shake (control) due to its better sensory appeal and high nutritive value and was more costeffective than the other two variants.

\section{Introduction}

Milk shake is a western dairy product obtained by freezing a mix very similar to soft serve ice cream mix and speedy mixing the frozen product in a mixer to make it pourable and generate foam in it. The milk shake that are commonly sold in the India subcontinent consist of sweetened cold milk added with colouring and flavouring agents without freezing but vigorously shake. The most commonly used flavour blends are of rose, coffee and chocolate. Milk shake is sold by fruit juice centres in many parts of our country during the whole years. It is liked most by consumer as it is palatable and nutritional (Kadav, 2001).

Today's consumers are increasingly seeking functional foods for their health and well being as means of intervention in disease prevention. Due to the today's upward consumer awareness and interest to follow healthy nutrition and dietary strategy in 
achieving health benefits from food beyond their basic nutrition the market for value added foods has expanded manifolds. In the food processing industry the dairy sector has depicted value addition (35\%) whereas in the case of total agriculture it is only 2 per cent.

Almonds are one of the most nutritious of all nuts. Almonds are rich in vit. E (tocopherol) flavonoids and other antioxidants and it help in lowering the bad cholesterol. Almond is very low in carbohydrate so it is perfect for low carbohydrate diets. It can help in burning fat because it is low in calories. Almonds are rich source of some essential minerals such as magnesium and calcium. Almond contains copper in organic form @ 15 mg per 100 gm, almonds are therefore useful food for consumer. Sweet almond oil is one of the most popular oil used in aromatherapy. Regular consumption of almond all helps to reduce cholesterol, nourishment of brain and enhances intellectuality. It has been seem to be beneficial in combating life style decrease such as cardiovascular disease. Almond helps in fighting diabetics and heart disease.

Several types of milk shake are sold in the market i.e. mango milk shake, sapota milk shake, fig milk shake, banana milk shake, almond milk shake, custard apple milk shake and the method of manufacture of milk shake vary from region to region. The base for all this type of milk shake is however milk and cane sugar in different proportion and other specific ingredient are incorporated to cater. The special taste, the milk shake shows wide variation in method of manufacture. No attempts have so for been made to formulate quality standard for this product. The paucity of adequate published information of almond milk shake, is the main constraint in determining the legal standard therefore it is an immediate need for standardizing suitable methodology for preparation almond milk shake so that the chemical quality of almond milk shake could become uniform.

\section{Materials and Methods}

The whole, fresh, clean buffalo milk was obtained from buffalo unit maintained at Department of Animal Husbandry and Dairy Science, College of Agriculture, Vasantrao Naik Marathwada Krishi Vidyapeeth, Parbhani. Milk was standardized to 6 per cent of fat and 9 per cent SNF by Pearson's formula. Almond, Sugar and other ingredients were obtained from the local market of Parbhani. Different equipments viz., Karahi, Khunti, stainless steel trays, mixer grinder, etc were available in the department. Analytical reagent grade chemicals were used for the chemical analysis.

\section{Treatment details}

$\mathrm{T}_{0}=\quad$ Market almond milk shake (Control)

$\mathrm{T}_{1}=5$ parts crushed almond +95 parts

buffalo milk (w/w)

$\mathrm{T}_{2}=10$ parts crushed almond +90 parts

buffalo milk (w/w)

$\mathrm{T}_{3}=15$ parts crushed almond +85 parts

buffalo milk (w/w)

\section{Preparation of almond milk shake}

Almond milk shake was prepared by following the procedure as per Sharma and Gupta (1978) with slight modification. The measured quantity of fresh buffalo milk was filtered through muslin cloth. The buffalo milk was standardized to 6 per cent fat and 9 per cent SNF. Milk was kept in karahi for heating and sugar was added @ 10. The crushed Almonds were added @ 5,10 and 15 parts as per level of treatment. It was mixed well, kept in deep freezer and blended in mixer and almond milk shake was ready to serve. 
Flow diagram of preparation of almond milk shake

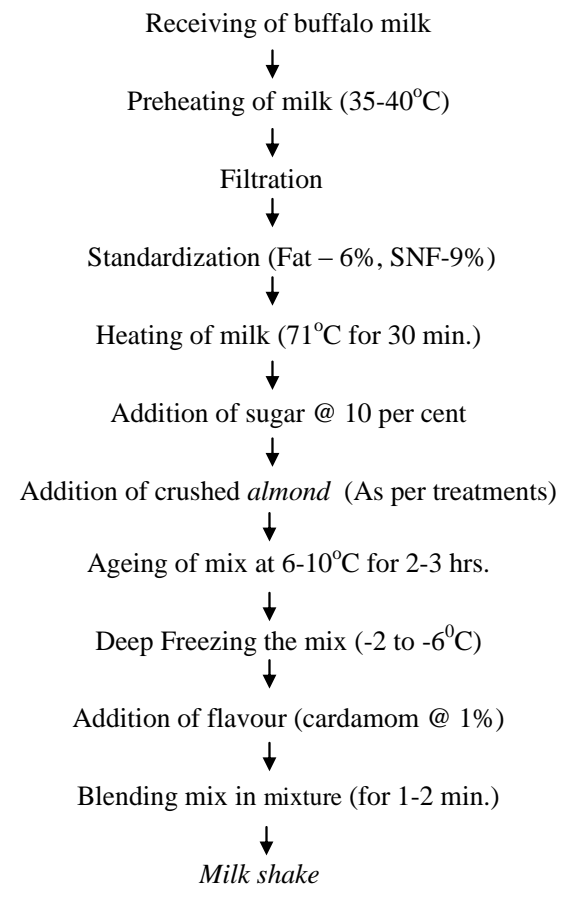

\section{Sensory evaluation}

The sensory characteristics, viz., colour and appearance, flavour, body and texture and overall acceptability were evaluated by a panel of five assessors using "9-point Hedonic scale" developed by Quarter Master, Food and Container Institute, USA (Gupta, 1976). The scores ranged between 1 and 9 , depending upon the liking. The descriptors were, extremely liked (9), liked very much (8), liked moderately (7), liked slightly (6), neither liked nor disliked (5), disliked slightly (4), disliked moderately (3), disliked very much (2) and extremely disliked (1). The scores were pooled and mean score for overall acceptability was worked out (Fig. 1).

\section{Cost of production}

The ingredients required for preparation of almond milk shake was calculated on the basis of prevailing market price and cost per liter of almond milk shake was worked out.
The cost towards fuel and other items was considered under miscellaneous charges.

\section{Statistical analysis}

The data were subjected to statistical analysis by using Completely Randomized Design as described by Panse and Sukhatme (1967).

\section{Results and Discussion}

The values for proximate composition, sensory evaluation and production cost parameter are presented in Table 1 and 2.

\section{Sensory evaluation of almond milk shake}

The almond milk shake prepared from different blends of crushed almonds and buffalo milk was subjected to sensory evaluation and scores recorded for different parameter.

\section{Colour and appearance}

The mean colour and appearance score for different treatment of almond milk shake ranged from 7.95 to 7.97 . The treatment $T_{1}$ (8.33) was found to be significantly superior over the rest of the treatments. It was observed that increased level of almond in almond milk shake also increased the score of colour and appearance slightly. The results obtained for colour and appearance were comparable with those of Pakalwad et al., (2010) observed that the colour and appearance score for different treatment of papaya milk shake ranged from 8.07 to 8.33 . Mule et al., (2014) stated that the score of appearance for fig milk shake ranged between 8.06 and 8.38 .

\section{Flavour}

It was observed from Table 1 that, the mean score for flavour of almond milk shake for treatments $\mathrm{T}_{0}, \mathrm{~T}_{1}, \mathrm{~T}_{2}$ and $\mathrm{T}_{3}$ was 8.03, 8.52, 
8.47 and 8.22 , respectively. The treatment $T_{1}$ was significantly superior over $\mathrm{T}_{0}$ and $\mathrm{T}_{3}$ treatments. However, the flavour score of treatments $T_{2}$ was at par with treatment $T_{1}$. It was observed from above findings that 95 per cent buffalo milk blended with 5 per cent almond gave rich flavour to milk shake. The results obtained in this study are in close agreement with those of Pakalwad et al., (2010) observed that the mean score flavour of papaya milk shake ranged from 8.15 to 8.52. Mule et al., (2014) reported that the mean score of flavour for fig milk shake in between 8.04 to 8.29 .

Table.1 Sensory parameter of almond milk shake

\begin{tabular}{|l|c|c|c|c|c|c|}
\hline \multicolumn{1}{|c|}{ Parameter } & Control & $\mathbf{5 \%}$ almond & $\mathbf{1 0 \%}$ almond & $\mathbf{1 5 \%}$ almond & S.E. & CD at 5\% \\
\hline Colour \& Appearance & 7.95 & 8.33 & 8.24 & 7.97 & 0.024 & 0.075 \\
\hline Flavour & 8.03 & 8.52 & 8.47 & 8.22 & 0.054 & 0.016 \\
\hline Body \& Texture & 8.22 & 8.49 & 8.36 & 8.18 & 0.12 & 0.37 \\
\hline Overall acceptability & 8.06 & 8.44 & 8.35 & 8.12 & 0.10 & 0.30 \\
\hline
\end{tabular}

Table.2 Production cost of almond milk shake for $1 \mathrm{Kg}$

\begin{tabular}{|c|c|c|c|c|c|c|c|c|}
\hline \multirow{2}{*}{$\begin{array}{l}\text { Sr. } \\
\text { No }\end{array}$} & \multirow[t]{2}{*}{ Components } & \multirow{2}{*}{$\begin{array}{l}\text { Unit Cost } \\
\text { (Rs.) }\end{array}$} & \multicolumn{2}{|c|}{ 5\% Almond } & \multicolumn{2}{|c|}{$10 \%$ Almond } & \multicolumn{2}{|c|}{$15 \%$ Almond } \\
\hline & & & $\begin{array}{l}\text { Qty. } \\
\text { (g) }\end{array}$ & $\begin{array}{l}\text { Amt. } \\
\text { (Rs.) }\end{array}$ & $\begin{array}{l}\text { Qty. } \\
\text { (g) }\end{array}$ & $\begin{array}{l}\text { Amt. } \\
\text { (Rs.) }\end{array}$ & $\begin{array}{l}\text { Qty. } \\
\text { (g) }\end{array}$ & $\begin{array}{l}\text { Amt. } \\
\text { (Rs.) }\end{array}$ \\
\hline 1 & Buffalo milk & 40/ litre & 950 & 38.00 & 900 & 36.00 & 850 & 34.00 \\
\hline 2 & Sugar & $25 / \mathrm{kg}$ & 100 & 2.5 & 100 & 2.5 & 100 & 2.5 \\
\hline 3 & Almond & $900 / \mathrm{kg}$ & 50 & 45 & 100 & 90 & 150 & 135 \\
\hline 4 & Cardamom & $2000 / \mathrm{kg}$ & 1 & 2 & 1 & 2 & 1 & 2.00 \\
\hline 5 & Labour & $1.5 / \mathrm{h}$ & 1 & 1.5 & 1 & 1.5 & 1 & 1.5 \\
\hline 6 & Electricity & 0.50 & -- & 0.50 & -- & 0.50 & -- & 0.50 \\
\hline 7 & Fuel & 5.00 & -- & 5.00 & -- & 5.00 & -- & 5.00 \\
\hline 8 & Miscellaneous & 5.00 & -- & 5.00 & -- & 5.00 & -- & 5.00 \\
\hline & Total & -- & -- & 99.5 & -- & 142.5 & -- & 185.5 \\
\hline
\end{tabular}


Fig.1 Effect of different levels of crushed almond on overall acceptability score of almond milk shake

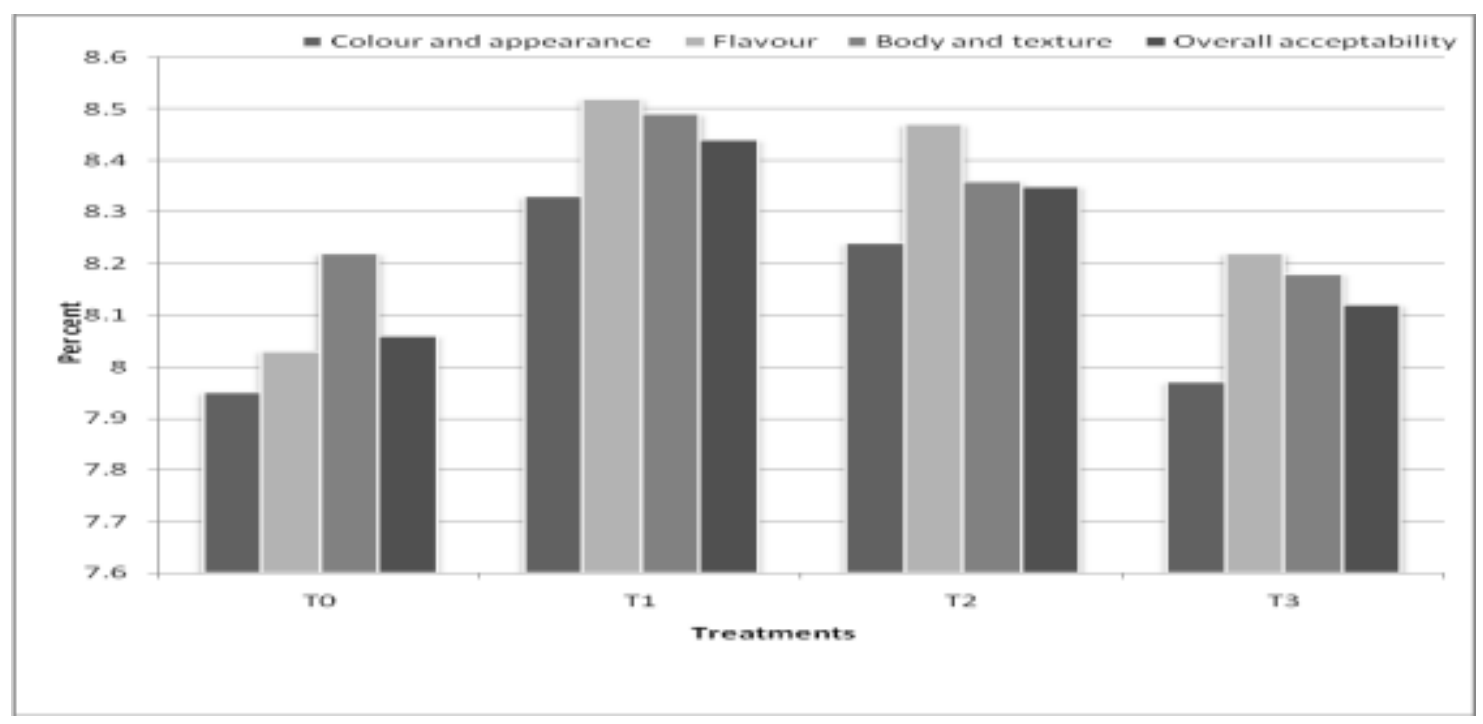

\section{Body and texture}

The mean score for the body and texture attributes of almod milk shake it was in the range of 8.22 to 8.18 . The score recorded seems to be highest for $\mathrm{T}_{1}(8.49)$ and lowest 8.18 as $\left(\mathrm{T}_{3}\right)$. The treatment $\mathrm{T}_{1}(8.49)$ was significantly superior over rest of the treatments. The body and texture score for treatment $\mathrm{T}_{1}$ and $\mathrm{T}_{2}$ were at par with each other. The addition of almond in the blend, improve the body and texture of the milk shake. The results obtained are in agreement with those of Kashid (2005) prepared almond milk shake from cow milk blended with safflower milk and reported the body and texture score for almond milk shake varied from 7.41 to 8.21. Mule et al., (2014) observed that the score of texture for fig milk shake ranged between 8.16 and 8.29.

\section{Overall acceptability}

The mean score for treatment $\mathrm{T}_{0}, \mathrm{~T}_{1}, \mathrm{~T}_{2}$ and $\mathrm{T}_{3}$ were $8.06,8.44,8.35$ and 8.12 respectively. The treatment $\mathrm{T}_{3}$ (8.12) having least overall acceptability score. The treatment $\mathrm{T}_{1}$ (8.44) was most acceptable by the judges. So that, 5 per cent level of almond was most acceptable but the other treatment combinations are also acceptable but in descending value. The mean score of overall acceptability showed decreasing trend, i.e. with increase in level of almond, there was a decrease in the acceptability of the finished product. The results recorded in this study in comparable with the results obtained by Pakalwad et al., (2010) observed that the overall acceptability score for different treatment of papaya milk shake ranged from 8.03 to 8.56. Mule et al., (2014) stated that the mean score of fig milk shake for overall acceptability ranged between 8.11 and 8.30 .

\section{Production cost}

It was observed from Table 2, the cost of the production of almond milk shake per $\mathrm{kg}$ for treatment $\mathrm{T}_{0}, \mathrm{~T}_{1}, \mathrm{~T}_{2}$ and $\mathrm{T}_{3}$ was Rs.54.5, 99.5, 142.5 and 185.5 , respectively. The almond milk shake prepared from buffalo milk and almond (95 per cent buffalo milk and 5 per cent almond) $T_{1}$ was most accepted to the judges. It was costlier than normal (control) milk shake. The treatment $T_{1}$ was economical than rest of the treatments. Treatment $\mathrm{T}_{1}$ 
scored the highest score by the panel of judges and rated between like very much to like extremely. The results obtained in this study are in agreement with those of Mule (2014) who prepared fig milk shake and reported production cost of finished product ranged as Rs. 73.50 to $90.00 /$ lit.

In conclusion, the almond milk shake is very refreshing, high in nutritive value and was prized for its medicinal properties. Almond milk shake product would be more palatable and nutritive. All the levels of crushed almond in milk shake i.e. 5, 10 and 15 per cents were acceptable but the optimum level of almond could be incorporated in the blend up to 5 per cent was most acceptable and cost efficient. The higher proportion crushed almond utilized in the blend scored towards lower side by panel of judges.

\section{References}

Gupta, S.K. 1976. Sensory evaluation in food industry. Indian Dairyman, 28(7): 293 295.
Kadav, V.B. 2001. Preparation of fruit flavoured milk shake. M.Sc. Thesis submitted to Dr. B.S.K.K.V., Dapoli, Ratnagiri, M.S. (India).

Kashid, U.B. 2005. Preparation of golden milk shake from cow milk blended with safflower milk. M.Sc. (Agri.) Thesis, MKV, Parbhani (India).

Mule, P.R., Barbind, R.P., Korake, R.L. and Gavit, D.P. 2014. Proximate composition, sensory evaluation and production cost of fig milk shake prepared from buffalo milk. Animal Science Reporter, 8(2): 43-47.

Pakalwad, S.T., Awaz, H.B., Pawar, S.L. and Paul, S.P. 2010. Preparation and sensory evaluation of papaya milk shake. Veterinary world, 3(4): 185-187.

Panse, V.G. and Sukhatme, P.V. 1967. Statistical Methods for Agricultural Workers. $2^{\text {nd }}$ Edn., ICAR, New Delhi.

Sharma, A.K. and Gupta, S.K. 1978. Manufacture of milk shake. Indian Dairyman, 30(8):585.

\section{How to cite this article:}

Kuchekar, D.D., S.G. Narwade and Gaikwad, S.V. 2019. Sensory Evaluation and Production Cost of Almond Milk Shake. Int.J.Curr.Microbiol.App.Sci. 8(01): 2077-2082. doi: https://doi.org/10.20546/ijcmas.2019.801.217 